\title{
Intramyocellular lipid content is increased after exercise in nonexercising human skeletal muscle
}

Citation for published version (APA):

Schrauwen-Hinderling, V. B., van Loon, L. J. C., Koopman, R., Nicolay, K., Saris, W. H. M., \& Kooi, M. E. (2003). Intramyocellular lipid content is increased after exercise in nonexercising human skeletal muscle. Journal of Applied Physiology, 95(6), 2328-2332. https://doi.org/10.1152/japplphysiol.00304.2003

Document status and date:

Published: 01/01/2003

DOI:

10.1152/japplphysiol.00304.2003

Document Version:

Publisher's PDF, also known as Version of record

\section{Please check the document version of this publication:}

- A submitted manuscript is the version of the article upon submission and before peer-review. There can be important differences between the submitted version and the official published version of record.

People interested in the research are advised to contact the author for the final version of the publication, or visit the DOI to the publisher's website.

- The final author version and the galley proof are versions of the publication after peer review.

- The final published version features the final layout of the paper including the volume, issue and page numbers.

Link to publication

\footnotetext{
General rights rights.

- You may freely distribute the URL identifying the publication in the public portal. please follow below link for the End User Agreement:

www.umlib.nl/taverne-license

Take down policy

If you believe that this document breaches copyright please contact us at:

repository@maastrichtuniversity.nl

providing details and we will investigate your claim.
}

Copyright and moral rights for the publications made accessible in the public portal are retained by the authors and/or other copyright owners and it is a condition of accessing publications that users recognise and abide by the legal requirements associated with these

- Users may download and print one copy of any publication from the public portal for the purpose of private study or research.

- You may not further distribute the material or use it for any profit-making activity or commercial gain

If the publication is distributed under the terms of Article $25 \mathrm{fa}$ of the Dutch Copyright Act, indicated by the "Taverne" license above, 


\title{
Intramyocellular lipid content is increased after exercise in nonexercising human skeletal muscle
}

\author{
V. B. Schrauwen-Hinderling, ${ }^{1-3}$ L. J. C. van Loon, ${ }^{2}$ R. Koopman, ${ }^{2}$ \\ K. Nicolay, ${ }^{3}$ W. H. M. Saris, ${ }^{2}$ and M. E. Kooi ${ }^{1}$ \\ ${ }^{1}$ Department of Radiology, University Hospital Maastricht, 6229 HX Maastricht; ${ }^{2}$ Nutrition Research Institute \\ Maastricht, Maastricht University, 6200 MD Maastricht; and ${ }^{3}$ Department of Biomedical Engineering, \\ Eindhoven University of Technology, 5612 AZ Eindhoven, The Netherlands
}

Submitted 25 March 2003; accepted in final form 5 August 2003

\begin{abstract}
Schrauwen-Hinderling, V. B., L. J. C. van Loon, R. Koopman, K. Nicolay, W. H. M. Saris, and M. E. Kooi. Intramyocellular lipid content is increased after exercise in nonexercising human skeletal muscle. J Appl Physiol 95: 2328-2332, 2003. First published August 15, 2003; 10.1152/ japplphysiol.00304.2003.--Intramyocellular lipid (IMCL) content has been reported to decrease after prolonged submaximal exercise in active muscle and, therefore, seems to form an important local substrate source. Because exercise leads to a substantial increase in plasma free fatty acid (FFA) availability with a concomitant increase in FFA uptake by muscle tissue, we aimed to investigate potential differences in the net changes in IMCL content between contracting and noncontracting skeletal muscle after prolonged endurance exercise. IMCL content was quantified by magnetic resonance spectroscopy in eight trained cyclists before and after a 3 -h cycling protocol (55\% maximal energy output) in the exercising vastus lateralis and the nonexercising biceps brachii muscle. Blood samples were taken before and after exercise to determine plasma FFA, glycerol, and triglyceride concentrations, and substrate oxidation was measured with indirect calorimetry. Prolonged endurance exercise resulted in a $20.4 \pm 2.8 \%(P<0.001)$ decrease in IMCL content in the vastus lateralis muscle. In contrast, we observed a substantial $(37.9 \pm 9.7 \% ; P<0.01)$ increase in IMCL content in the less active biceps brachii muscle. Plasma FFA and glycerol concentrations were substantially increased after exercise (from $85 \pm 6$ to $1,450 \pm 55$ and $57 \pm 11$ to $474 \pm 54 \mu \mathrm{M}$, respectively; $P<0.001$ ), whereas plasma triglyceride concentrations were decreased (from 1,498 \pm 39 to $703 \pm 7 \mu \mathrm{M} ; P<$ $0.001)$. IMCL is an important substrate source during prolonged moderate-intensity exercise and is substantially decreased in the active vastus lateralis muscle. However, prolonged endurance exercise with its concomitant increase in plasma FFA concentration results in a net increase in IMCL content in less active muscle.
\end{abstract}

intramuscular triglycerides; inactive muscle; fat oxidation; magnetic resonance spectroscopy

DURING SUBMAXIMAL exercise, fat and carbohydrate form the main substrates for the exercising muscle. Stable isotope studies have shown that $\sim 50 \%$ of total fat oxidation is accounted for by plasma free fatty acid

Address for reprint requests and other correspondence: V. B Schrauwen-Hinderling, Univ. Hospital Maastricht, Dept. of Radiology, P.O. Box 5800, 6202 AZ Maastricht, The Netherlands (E-mail: vhi@rdia.azm.nl).
(FFA) oxidation, suggesting that other fat sources play a substantial role in energy provision $(8,14,21)$. Other fat sources include intramuscular lipid stores $(4,5)$ and lipoprotein-derived triglycerides (10). Recent studies using ${ }^{1} \mathrm{H}$-magnetic resonance spectroscopy (MRS) have shown that intramyocellular lipid (IMCL) content is decreased after prolonged endurance exercise in active muscle $(4,7,13,17)$. This suggests that IMCL oxidation contributes significantly to total energy expenditure. From the net depletion of IMCL content measured before and after a marathon run, Boesch et al. (2) estimated that between 11 and 26\% of the energy provided by fat oxidation had originated from IMCL breakdown.

As stated above, oxidation of IMCL and lipoproteinderived triglycerides contributes substantially to fat oxidation during exercise; however, the largest contribution is thought to come from plasma FFA. During prolonged endurance exercise, adipose tissue lipolysis is substantially increased to enable ample provision of plasma FFA to the working muscle. However, the release of fatty acid (FA) by lipolysis exceeds the oxidation capacity of the working muscle, as it has been shown that only $70-90 \%$ of the rate of disappearance of FFA is oxidized to $\mathrm{CO}_{2}(20,21)$. The remaining part of FA taken up might be reesterified in adipose tissue, liver, and exercising or nonexercising skeletal muscle. The contribution of adipose tissue is considered to be very small (19), and hepatic reesterification was estimated to account for $24 \%$ of total reesterification (19). Skeletal muscle has been shown to take up and reesterify FFA during exercise (19). Muscle contraction strongly increases the percentage of plasma FFA that is routed toward oxidation, leading to a net decrease in muscle triglyceride during exercise. In noncontracting muscle, however, the abundance of FFA during exercise could lead to an increase in muscle triglycerides.

Under resting conditions, skeletal muscle is capable of clearing FFA from plasma, and elevated plasma FFA concentrations lead to a net accumulation of IMCL. Infusions of triglyceride-heparin (1), $72 \mathrm{~h}$ of fasting

The costs of publication of this article were defrayed in part by the payment of page charges. The article must therefore be hereby marked "advertisement" in accordance with 18 U.S.C. Section 1734 solely to indicate this fact. 
(18), as well as 3 days of high-fat diet all lead to elevated plasma FFA levels and an increased IMCL content. Therefore, it is generally thought that, during resting conditions, elevated plasma FFA concentrations stimulate reesterification of FA in skeletal muscle. However, during exercise, lipolysis is stimulated in adipose tissue as well as in skeletal muscle. Although prolonged moderate- to high-intensity exercise leads to a net decrease in IMCL content in contracting muscle, it could be speculated that, similar to the observations at rest, IMCL content is increased in noncontracting muscle.

In the present study, we measured IMCL content in both exercising leg muscle and nonexercising arm muscle before and after a 3-h cycling protocol. If oxidation rate outweighs the rate of reesterification in contracting muscle, we would expect IMCL content in the exercising leg muscle to decrease. Analogously, if reesterification rate exceeds FFA oxidation rate in noncontracting muscle, a net increase in IMCL content in the nonexercising arm muscle should be observed.

\section{MATERIALS AND METHODS}

\section{Subjects}

Eight young [age: $24 \pm 3$ (SD) yr], highly trained [maximal energy output (Wmax) per kilogram: $5.8 \pm 0.46$ ] male cyclists participated in this study. The study was approved by the institutional Medical Ethics Committee. Subjects gave their written, informed consent after the nature of the procedure and possible risks were explained.

\section{Experimental Protocol}

Before the test days, subjects received a standardization $\operatorname{diet}(13 \pm 1 \%$ of energy as protein, $56 \pm 3 \%$ as carbohydrate, and $30 \pm 1 \%$ as fat) for 3 days during which they refrained from exercise. On the test day, subjects reported to the laboratory in the early afternoon. A baseline ${ }^{1} \mathrm{H}-\mathrm{MRS}$ scan was performed to quantify IMCL content in the vastus lateralis and the biceps brachii muscle. Subsequently, a blood sample was collected $(7 \mathrm{ml})$. A 3-h cycling protocol was then performed. After 5 min of warming up at $100 \mathrm{~W}$, subjects cycled for $3 \mathrm{~h}$ at $55 \%$ of their Wmax, which averaged $231 \pm 19$ W. During the exercise trial, oxygen uptake $\left(\dot{\mathrm{V}}_{2}\right)$ and carbon dioxide production $\left(\mathrm{V}_{\mathrm{CO}_{2}}\right)$ were measured every $30 \mathrm{~min}$ continuously over 10-min intervals (Oxycon- $\beta$, Mijnhardt, Mannheim, Germany). From respiratory measurements, total fat and carbohydrate oxidation rates were calculated by using the nonprotein respiratory quotient as given below (12)

$$
\text { Fat oxidation rate }=1.695 \dot{\mathrm{V}}_{2}-1.701 \dot{\mathrm{V}}_{2}
$$

Carbohydrate oxidation rate $=4.585 \dot{\mathrm{V}}_{\mathrm{CO}_{2}}-3.226 \dot{\mathrm{V}}_{2}$

with $\dot{\mathrm{V}}_{2}$ and $\dot{\mathrm{V}}_{\mathrm{CO}_{2}}$ in liters per minute and oxidation rates in grams per minute.

Subjects were allowed to drink water ad libitum during cycling. After cessation of exercise, subjects were allowed a quick shower (maximum 5 min), after which a second blood sample was taken. Immediately after this, a second MRS measurement was performed to quantify IMCL content in the leg and subsequently in the arm muscle.

\section{Procedures}

MRS measurement. Image-guided, localized, single-voxel ${ }^{1} \mathrm{H}$-MRS was performed in the vastus lateralis and the biceps brachii muscle before and immediately after the 3-h cycling test. The measurements were performed on a $1.5-\mathrm{T}$ whole body scanner (Intera, Philips Medical Systems, Best, the Netherlands) with a flexible surface coil wrapped around the upper leg and arm, with the extremity placed in the parallel position with the $\mathrm{B}_{0}$ magnetic field.

In every subject, voxels were carefully placed at the same position for repeated measurements. Care was taken to avoid vascular structures and adipose tissue deposits within the voxel. To reproduce the same voxel position, the longitudinal distance of the voxel from the intercondylar eminence of the knee joint or from the elbow was determined in a coronal image. T2-weighted turbo spin-echo magnetic resonance images, consisting of five transversal slices, were acquired at this position (slice thickness: $5 \mathrm{~mm}$, repetition time: 2,000 ms, echo time: $85 \mathrm{~ms}$, echo train length: 12, field of view: 210 $\mathrm{mm}$, and matrix size: $256 \times 256$ ). The patterns of the fat distribution were used to verify the longitudinal position and as landmarks to reproduce the voxel position in the transversal plane.

${ }^{1} \mathrm{H}$-MRS spectra from the regions of interest were acquired by using a point-resolved spectroscopy sequence with the following acquisition parameters: repetition time: $3,000 \mathrm{~ms}$, echo time: $25 \mathrm{~ms}$; 16 -phase cycles, 128 averages; 1,024 data points over $1,000-\mathrm{Hz}$ spectral width. The voxel volume was $(12 \times 11 \times 18) \mathrm{mm}^{3}$. The water signal was suppressed by using chemically selective saturation. The unsuppressed water signal was subsequently measured in the same voxel under the same shimming conditions and was used as a reference signal.

Postprocessing. The spectra were fitted in the time domain by using a nonlinear least squares algorithm [AMARES (22)] in the jMRUI software package (9) (http://www.mrui.uab.es/ mrui/). Three peaks were fitted for IMCL (I1, I2, and I3 in Fig. 1) and three peaks for extramyocellular lipids (EMCL) (E1, E2, and E3 in Fig. 1). Prior knowledge of the relative peak positions (3) and area ratios (C. Boesch, private communication) as determined by Boesch and colleagues was used as a constraint. To increase the accuracy and reliability of the fitting procedure in the vastus lateralis muscle, the line width of the $\mathrm{CH}_{2}$ peak of IMCL (I2 in Fig. 1A) was fixed relative to the line width of the unsuppressed water peak (measured in the same voxel), and soft constraints were used on the line width and the position of the EMCL peak. In the biceps brachii muscle, these additional constraints were unnecessary. IMCL and EMCL peaks were fitted with a Gaussian curve, whereas water peaks were fitted with a Lorenztian curve. The signals were corrected for $\mathrm{T} 1$ and $\mathrm{T} 2$ relaxation by using the T1 and T2 relaxation times as determined by Schick et al. (16). The corrected area of the $\mathrm{CH}_{2}$ peak of IMCL was expressed relative to the area of the water peak.

\section{Analysis}

Blood analyses. Samples of venous blood $(7 \mathrm{ml})$ were obtained in EDTA-coated tubes and immediately centrifuged at high speed $\left(1,000 \mathrm{~g}, 4^{\circ} \mathrm{C}\right)$ for $10 \mathrm{~min}$. Plasma was immediately frozen in liquid nitrogen and stored at $-80^{\circ} \mathrm{C}$ until analyses for FFA (Wako NEFA test kid, Wako chemicals, Neuss, Germany), free glycerol (148270, Roche Diagnostics, Indianapolis, IN), and triacylglycerol (GPO-trinder 337B, Sigma Diagnostics, St. Louis, MO) on a COBAS FARA semiautomatic analyzer (Roche, Basel, Switzerland).

Statistics. Characteristics of subjects and diet composition are reported as means $\pm \mathrm{SD}$, whereas results are reported as means \pm SE. Statistical analyses were performed with SPSS for Windows 10.0.0 software (SPSS, Chicago, IL). Differences 

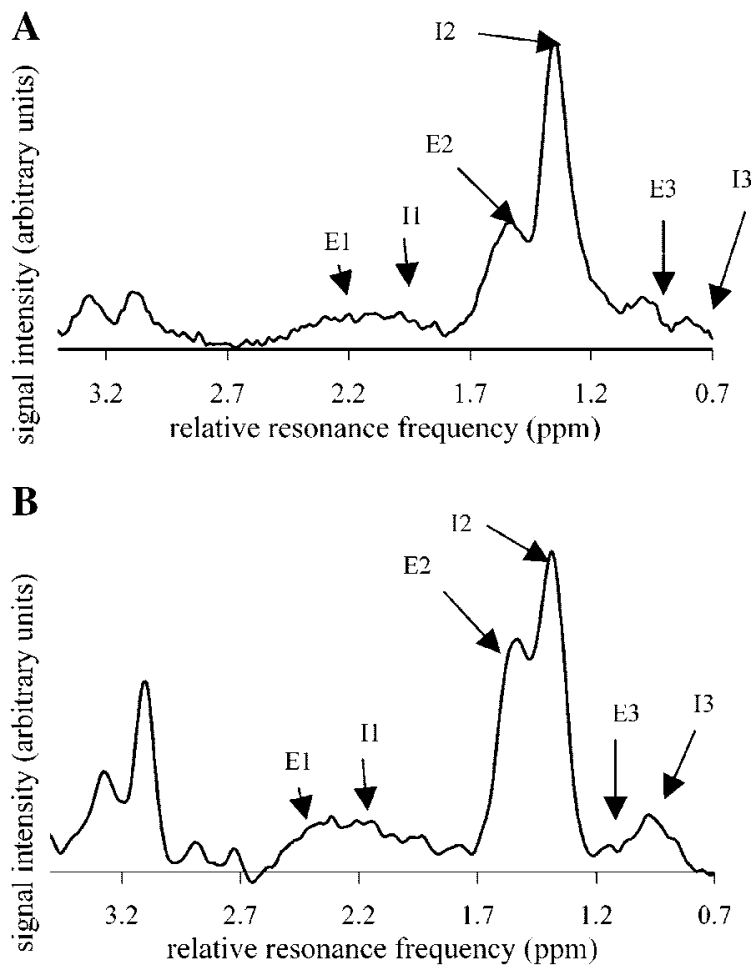

Fig. 1. Typical spectra of the vastus lateralis muscle $(A)$ and biceps brachii muscle $(B)$. Extramyocellular lipid peaks are depicted as E1-E3; intramyocellular lipid (IMCL) peaks are depicted as I1-I3. ppm, Parts/million.

in values before and after exercise were detected with a paired $t$-test. Results were considered significant if $P<0.05$.

\section{RESULTS}

\section{Substrate Oxidation}

Whole body fat oxidation increased continuously during the 3 -h cycling protocol, whereas carbohydrate oxidation decreased (see Fig. 2). Subjects oxidized on average $91 \pm 4 \mathrm{~g}$ of fat and $494 \pm 17 \mathrm{~g}$ of carbohydrate during the exercise protocol. The total energy expenditure amounted to $11.7 \pm 0.2 \mathrm{MJ}$. The relative contribution of fat oxidation to the total energy expenditure

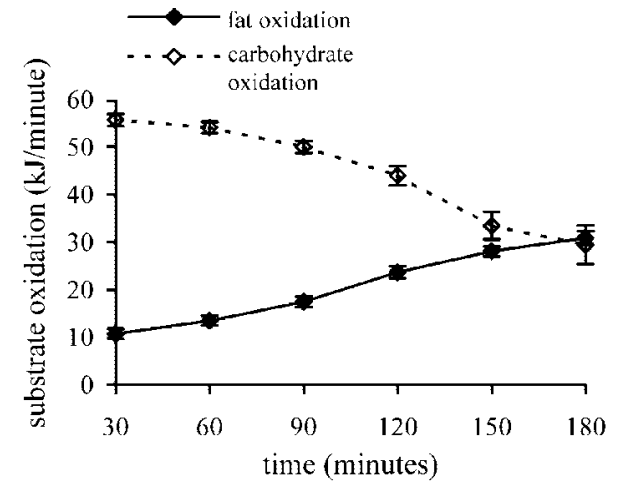

Fig. 2. Average fat and carbohydrate oxidation during the 3-h cycling protocol. Values are means $\pm \mathrm{SE}$. Solid line and $\bullet$, fat oxidation; dashed line and $\diamond$, carbohydrate oxidation. was $32 \pm 1 \%$, whereas the relative contribution of carbohydrates was $68 \pm 1 \%$.

\section{Blood Parameters}

Plasma FFA concentrations increased during exercise $(85 \pm 6$ and $1,450 \pm 55 \mu \mathrm{M}$ before vs. after exercise, respectively, $P<0.001$ ). Glycerol concentrations also increased ( $57 \pm 11$ and $474 \pm 54 \mu \mathrm{M}$ before and after exercise, respectively, $P<0.001$ ), whereas triacylglycerol concentrations decreased during exercise $(1,498 \pm 139$ and $703 \pm 57 \mu \mathrm{M}$ before and after exercise, respectively, $P<0.001$ ).

\section{IMCL and EMCL Content}

Baseline IMCL content was four times higher in the vastus lateralis muscle compared with the biceps brachii muscle $(P<0.001)$. IMCL content at baseline was $0.61 \pm 0.05 \%$ of the water resonance in the vastus lateralis muscle and decreased by $20.4 \pm 2.8 \%(P<$ 0.001 , see Fig. $3 A$ ). The EMCL content did not change significantly $(0.39 \pm 0.06 \%$ before vs. $0.36 \pm 0.06 \%$ after exercise, $P=0.3$ ). In the nonexercising biceps brachii muscle, IMCL content at baseline was $0.14 \pm$ $0.02 \%$ of the water resonance and increased after exercise by $37.9 \pm 9.7 \%(P<0.01$, see Fig. $3 B)$. The EMCL content did not change significantly $(0.15 \pm$ $0.03 \%$ before vs. $0.15 \pm 0.01 \%$ after exercise, $P=1.0$ ).

If values are converted to millimoles per kilogram muscle wet weight, as described by Boesch et al. (2), IMCL content is $7.8 \pm 0.4$ and $6.2 \pm 0.5 \mathrm{mmol} / \mathrm{kg}$ in the vastus lateralis muscle and $1.8 \pm 0.2$ and $2.5 \pm 0.3$ $\mathrm{mmol} / \mathrm{kg}$ in the biceps brachii muscle before and after exercise, respectively.
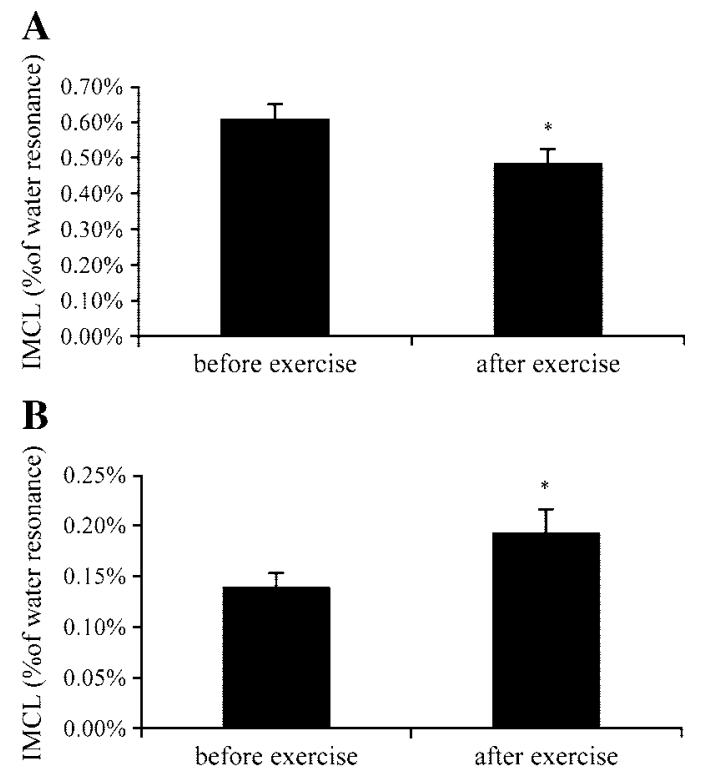

Fig. 3. IMCL content in the vastus lateralis muscle $(A)$ and biceps brachii muscle $(B)$ before and after the 3 -h cycling protocol $(n=8)$. Content is expressed as percentage of the $\mathrm{CH}_{2}$ peak of IMCL relative to the water signal. Values are means $\pm \mathrm{SE}$. * Significant differences between values before and after exercise $(P<0.05)$. 


\section{DISCUSSION}

The most important finding of the present study is that IMCL content in the less active muscle of the arm increased during prolonged submaximal cycling exercise, whereas we confirm earlier reports of decreasing IMCL content in the working leg muscle $(4,7,13,17)$. We suggest that, from the increased plasma FFA levels and subsequent increase in FFA uptake during exercise, a large portion of FA is routed toward oxidation in contracting muscle, whereas, in noncontracting muscle, plasma FFA uptake leads to a net accumulation of IMCL. This is in line with results from stable isotope studies from Sacchetti et al. (15), who describe a net uptake and partial resynthesis of FFA by nonexercising leg muscle during one-legged exercise.

Others have reported that elevated FFA plasma concentrations increase uptake under resting conditions. Boden et al. (1) reported that an increase in FFA (due to lipid-heparin infusions) during $3 \mathrm{~h}$ resulted in an increased IMCL content in the soleus muscle, with the increase in IMCL content correlating with the FFA plasma concentrations. In addition, Stannard et al. (18) observed that the increase in FFA concentration during $72 \mathrm{~h}$ of fasting was accompanied by elevated IMCL content. Similarly, in the present study, FFA levels increased during exercise, and the IMCL content in the biceps brachii muscle was elevated after exercise. These results suggest that, also in a physiological situation such as during exercise, relatively short-term elevated FFA concentrations lead to accumulation of IMCL in nonexercising muscle, thereby contributing to the clearance of FFA from plasma. As FFA are generally thought to be toxic at higher concentrations, it is important that plasma FFA concentrations be controlled. Inactive skeletal muscle seems to contribute to this control by acting as a buffer for FFA.

In contrast to the biochemical quantification of lipids in biopsy studies, the MRS technique enables us to differentiate lipid signals from two compartments, namely IMCL droplets and adipose tissue between muscle cells $(\mathrm{EMCL})(4,16)$. However, possible limitations of the technique should be considered. If the peaks are not clearly separated, the IMCL signal could be contaminated by the neighboring EMCL signal. In the present study, the EMCL and IMCL peaks are separated by $0.17 \mathrm{parts} / \mathrm{million}$ on average, which is typical for the vastus lateralis muscle (6) and which is sufficient for the quantification of the two peaks. Furthermore, the EMCL-to-IMCL ratio in the population of the highly trained athletes of the present study is relatively low, and, therefore, contamination of the IMCL by the EMCL signal is expected to be relatively low as well.

Lactate, which accumulates in muscle at high-intensity exercise, resonates in the same frequency range as the lipid signals and could, in principle, contaminate the lipid signals. Therefore, we estimated the possible contribution of residual lactate to the lipid signals. The estimation is based on a half-time of lactate disappearance of $10.6 \mathrm{~min}$ (11), the delay of $30 \mathrm{~min}$ between the end of the cycling exercise and the actual spectroscopic measurement, and a lactate concentration of 11.6-15.6 $\mathrm{mmol} / \mathrm{kg}$ dry wt immediately after exercise (21). From these calculations, we conclude that the contribution of lactate to the lipid signals is $<0.5 \%$ in the present study.

Care should be taken when using the water signal as concentration reference, because water and electrolyte shifts during exercise are possible. An alternative would be to use total creatine as a reference. When using total creatine instead of water as internal standard in the present study, similar results were obtained. We chose to use the water peak as internal reference, because the use of the small peak of total creatine introduced some additional variability so that the average coefficient of variation of repeated measurements increased from an average of $6 \%$ with water to $11.5 \%$ with total creatine as a reference (17). Because no trends in water signal were found before vs. after exercise, we concluded that it is justified to use the water signal as internal standard in the present study.

We report considerably lower values of IMCL content in the biceps brachii muscle, compared with the IMCL content in the vastus lateralis muscle. This agrees with the finding by Boesch et al. (2) that IMCL content is highly variable between muscle groups and is in line with findings by Ward et al. (23), who also report lower IMCL content in forearm muscle compared with leg muscle.

The EMCL content did not change significantly with exercise, either in the arm or in the leg muscle. However, EMCL data should be interpreted with care, as EMCL content generally shows a high spatial variation (4). Small changes in voxel position can have a high impact on the EMCL signal intensity. Furthermore, the ratio of EMCL-to-IMCL content in the leg of highly trained athletes of the present study is relatively low. Therefore, contamination of the EMCL signal by the IMCL signal is possible.

From the finding that IMCL content is increased during exercise in nonexercising muscle, the question arises as to whether FFA could also be reesterified in exercising muscle. This might not result in a net increase in IMCL, because of the continuous oxidation of IMCL during contraction. However, the simultaneous reesterification and even stronger hydrolysis of triglycerides could result in a turnover of IMCL with a net decrease in IMCL content in exercising muscle. The turnover is not quantifiable by ${ }^{1} \mathrm{H}-\mathrm{MRS}$, because only IMCL content, but not flux, is measured with this method. Using stable isotopes, Sacchetti et al. (15) reported that FFA are reesterified in both contracting and noncontracting muscle during one-legged exercise. However, the rate of esterification was about four times higher in the noncontracting leg compared with the contracting leg. Although significant esterification took place also in the active leg, intramuscular lipid content was decreased by $30 \%$ after exercise. Because reesterification has been shown to take place also in contracting muscle, the depletion data of the leg in the 
present study represent net changes and cannot be directly interpreted as fat oxidation. However, the data can be interpreted as a minimal estimate of IMCL oxidation. In the study of Sacchetti et al. (15), no net increase in muscle triglyceride was found in the noncontracting leg muscle. This discrepancy with the present study could be due to a different exercise protocol used and different muscles investigated.

In conclusion, we report the capacity of noncontracting muscle to take up and reesterify FFA during physiologically elevated plasma FFA. During exercise, when peripheral lipolysis is stimulated to increase plasma FFA availability and substrate oxidation, a net accumulation of IMCL occurs in nonexercising muscle.

We gratefully acknowledge the enthusiastic support of the subjects who volunteered to participate in these trials.

\section{DISCLOSURES}

L. J. C. van Loon was supported with an individual fellowship from the Netherlands Organization for Scientific Research.

\section{REFERENCES}

1. Boden G, Lebed B, Schatz M, Homko C, and Lemieux S. Effects of acute changes of plasma free fatty acids on intramyocellular fat content and insulin resistance in healthy subjects. Diabetes 50: 1612-1617, 2001.

2. Boesch C, Decombaz J, Slotboom J, and Kreis R. Observation of intramyocellular lipids by means of ${ }^{1} \mathrm{H}$ magnetic resonance spectroscopy. Proc Nutr Soc 58: 841-850, 1999.

3. Boesch $\mathbf{C}$ and Kreis R. MR-spectroscopy (MRS) of different nuclei applied to human muscle: additional information obtained by 1H-MRS. Int J Sports Med 18, Suppl 4: S310-S312, 1997.

4. Boesch C, Slotboom J, Hoppeler H, and Kreis R. In vivo determination of intra-myocellular lipids in human muscle by means of localized ${ }^{1} \mathrm{H}-\mathrm{MR}$-spectroscopy. Magn Reson Med 37: 484-493, 1997.

5. Hoppeler H, Howald H, Conley K, Lindstedt SL, Claassen H, Vock P, and Weibel ER. Endurance training in humans: aerobic capacity and structure of skeletal muscle. J Appl Physiol 59: 320-327, 1985.

6. Kooi ME, Schrauwen P, Mensink M, Wagenmakers AJM, Kemerink GJ, Goossens G, Hinderling V, van Loon L, and Blaak EE. ${ }^{1} \mathrm{H}$ MRS of the intra-myocellular lipid content in the m. vastus lateralis. In: 9th Scientific Meeting of the International Society of Magnetic Resonance in Medicine ISMRM, Glasgow, UK 2001. Berkeley, CA: ISMRM, 2001.

7. Krssak M, Petersen KF, Bergeron R, Price T, Laurent D, Rothman DL, Roden M, and Shulman GI. Intramuscular glycogen and intramyocellular lipid utilization during prolonged exercise and recovery in man: a ${ }^{13} \mathrm{C}$ and ${ }^{1} \mathrm{H}$ nuclear magnetic resonance spectroscopy study. J Clin Endocrinol Metab 85: 748754, 2000.

8. Martin WH 3rd, Dalsky GP, Hurley BF, Matthews DE, Bier DM, Hagberg JM, Rogers MA, King DS, and Holloszy JO.
Effect of endurance training on plasma free fatty acid turnover and oxidation during exercise. Am J Physiol Endocrinol Metab 265: E708-E714, 1993.

9. Naressi A, Couturier C, Devos JM, Janssen M, Mangeat C, de Beer R, and Graveron-Demilly D. Java-based graphical user interface for the MRUI quantitation package. MAGMA 12: 141-152, 2001.

10. Oscai LB, Essig DA, and Palmer WK. Lipase regulation of muscle triglyceride hydrolysis. J Appl Physiol 69: 1571-1577, 1990.

11. Pan JW, Hamm JR, Hetherington HP, Rothman DL, and Shulman RG. Correlation of lactate and $\mathrm{pH}$ in human skeletal muscle after exercise by ${ }^{1} \mathrm{H}$ NMR. Magn Reson Med 20: 57-65, 1991.

12. Peronnet $\mathbf{F}$ and Massicotte $\mathbf{D}$. Table of nonprotein respiratory quotient: an update. Can J Sport Sci 16: 23-29, 1991.

13. Rico-Sanz J, Moosavi M, Thomas EL, McCarthy J, Coutts GA, Saeed N, and Bell JD. In vivo evaluation of the effects of continuous exercise on skeletal muscle triglycerides in trained humans. Lipids 35: 1313-1318, 2000.

14. Romijn JA, Coyle EF, Sidossis LS, Gastaldelli A, Horowitz JF, Endert E, and Wolfe RR. Regulation of endogenous fat and carbohydrate metabolism in relation to exercise intensity and duration. Am J Physiol Endocrinol Metab 265: E380-E391, 1993.

15. Sacchetti M, Saltin B, Osada T, and van Hall G. Intramuscular fatty acid metabolism in contracting and non-contracting human skeletal muscle. J Physiol 540: 387-395, 2002.

16. Schick F, Eismann B, Jung WI, Bongers H, Bunse M, and Lutz O. Comparison of localized proton NMR signals of skeletal muscle and fat tissue in vivo: two lipid compartments in muscle tissue. Magn Reson Med 29: 158-167, 1993.

17. Schrauwen-Hinderling VB, Schrauwen P, Hesselink MKC, van Engelshoven JMA, Nicolay K, Saris WHM, Kessels AGH, and Kooi ME. The increase in intramyocellular lipid content is a very early response to training. J Clin Endocrinol Metab 88: 1610-1616, 2003.

18. Stannard SR, Thompson MW, Fairbairn K, Huard B, Sachinwalla T, and Thompson $\mathbf{C H}$. Fasting for $72 \mathrm{~h}$ increases intramyocellular lipid content in nondiabetic, physically fit men. Am J Physiol Endocrinol Metab 283: E1185-E1191, 2002.

19. Van Hall G, Bulow J, Sacchetti M, Al Mulla N, Lyngso D, and Simonsen L. Regional fat metabolism in human splanchnic and adipose tissues; the effect of exercise. J Physiol 543: 1033-1046, 2002.

20. Van Hall G, Sacchetti M, Radegran G, and Saltin B. Human skeletal muscle fatty acid and glycerol metabolism during rest, exercise and recovery. J Physiol 543: 1047-1058, 2002.

21. Van Loon LJ, Greenhaff PL, Constantin-Teodosiu D, Saris WH, and Wagenmakers AJ. The effects of increasing exercise intensity on muscle fuel utilisation in humans. J Physiol 536: 295-304, 2001.

22. Vanhamme L, van den Boogaart A, and Van Huffel S. Improved method for accurate and efficient quantification of MRS data with use of prior knowledge. J Magn Reson 129: 35-43, 1997.

23. Ward JA, Enright A, and Thompson CH. In vivo assessment of intramyocellular lipid stores in the flexor digitorum superficialis. MAGMA 14: 61-212, 2001. 